\title{
Ileal orthotopic bladder replacement without stenting of the ureterointestinal anastomosis- IOyears observation
}

\begin{abstract}
Background: Stenting of ureterointestinal anastomosis is a standard precautionary measure, irrespective of the method of constructing the anastomosis; however no convincing scientific data exists to support this procedure.
\end{abstract}

Objective: Clinical assessment of patients-radical cystectomy and ileal orthotopic bladder replacement without requirement for stenting of the ureterointestinal anastomosis or suprapubic cystostomy.

Design, setting, and participants: To establish feasibility of ureterointestinal anastomosis without stenting. 426 radical cystectomies were performed between 1999 and 2009 .

Intervention(s): Ileal orthotopic bladder replacement with afferent loop was performed in 124 patients.

Measurements: The following were evaluated: frequency of postoperative symptomatic urinary tract infections, duration of peritoneal drainage, length of hospitalization, duration of surgery, number of ureteral strictures type and number of major perioperative complications.

Results and limitations: Symptomatic pyelonephritis was observed in 10 patients $(8 \%)$. The mean surgical time was 6.0 hours (4.5-9.0). The mean time of peritoneal drainage was 9.1 days (3-40). The mean time of hospitalization was 14.1days (7-40). Ureterointestinal anastomosis strictures were observed in 7 patients (5.6\%). Major postoperative complications were observed in 12 patients $(9.7 \%)$. Limitations: This is retrospective study without the control group.

Conclusions: Meticulous and a traumatic ureterointestinal anastomosis and efficient urine and mucus evacuation from the reservoir in our experience, removes the requirement for stenting of the ureterointestinal anastomosis.

Keywords: cystectomy, orthotopic bladder, bladder cancer, ureter, stents
Volume 2 Issue 3 - 2015

Kowal Pawel,' Lorenz Jerzy,' Dembowski Janusz,' Szydelko Tomasz,' Kolodziej Anna,' Kasprzak Jaroslaw,' Niezgoda Tadeusz,' Dudek Krzysztof,' Debinski Pawel,' Malkiewicz Bartosz,, ', Wozniak Slawomir Pawel,' Ilo Dapo, ${ }^{2}$ Tupikowski Krzysztof,' Zdrojowy Romuald'

'Department and Clinic of Urology, Wroclaw Medical University, Poland

${ }^{2}$ Queen Elizabeth Hospital, United Kingdom

Correspondence: Wozniak Slawomir Pawel, Wroclaw Medical University, Department and Clinic of Urology, Wroclaw, 26 Manton Road, Abbey Wood, Poland, Tel 0777253I562, Email wozniak.dr@gmail.com

Received: February 16,2015 | Published: April 06, 2015

\section{Introduction}

Radical cystectomy is a standard procedure in invasive urinary bladder cancers and in superficial high-risk cancers. The ileal orthotopic bladder replacement is the most efficient way to reconstruct the urinary tract, both in women and in men. ${ }^{1-4}$ Methods for orthotopic bladder construction described in literature recommend stenting of the ureterointestinal anastomosis as a standard precautionary procedure, irrespective of the method of constructing the anastomosis..$^{5-21}$ The rationale for stenting of the anastomosis includes protecting from the consequences of urine extravasation, and facilitating the fusion of intestinal and ureteral mucosa. Additionally, a tortuous ureter and oedema at the anastomotic site can lead to upper tract urinary stasis and both can be mitigated by preoperative stenting.

Furthermore, the evacuation of urine and retained mucus from the ileal reservoir is efficiently dealt with by the suprapubic cystostomy. Optimal duration of stenting remains a topic of much debate and suggestions from several author ranges from 7 to 14 postoperativedays. ${ }^{5-21}$ The procedure of radical cystectomy with orthotopic bladder replacement carries a high risk of complications, mostly in the early postoperative period. According to the data available in the literature, the risk of early complications is $23-27 \%{ }^{22-}$ ${ }^{24}$ One of the most common complications is acute pyelonephritis, which is observed in $1.3-12.3 \%$ of patients. ${ }^{25-27}$ Factors that predispose to the infection of the upper urinary tract are stents left in-situ and the necessity of regular and repeated flushing of the reservoir in the postoperative period. ${ }^{28,29}$

Urine leakage which does not require reoperation is observed in $0.3-6.6 \%$ of cases. ${ }^{25,26}$ Ureterointestinal anastomosis stricture as a late complication is observed in $2.2-11.6 \%$ of patients. ${ }^{26,30-34}$ The frequency of major complications, such as death, myocardial infarction, pulmonary embolism, septic shock, respiratory insufficiency or reoperation is $4.9-5 \%{ }^{25,35}$ Improvements in operative techniques and 
perioperative care have led to a reduction in the rates of complications post-radical cystectomy. Routine stenting of the ureterointestinal anastomosis has not been universally accepted and reports from transplantation cases have demonstrated higher risk of infection in comparison with the group of patients in whom stenting was not performed. According to some reports, stenting of the ureterointestinal anastomosis should be restricted to a selected group of patients. ${ }^{36-38}$

The number of studies on ureterointestinal anastomosis without stenting is limited, and their conclusions are ambiguous. ${ }^{39,40}$ In our opinion, refraining from stenting of the ureterointestinal anastomosis lowers the risk of upper urinary tract infections, reduces both surgical time and hospital stay and improves postoperative recovery without exposure of the patient to any additional risk of complications. Clinical evaluation was performed on a group of patients in whom neither stenting of ureterointestinal anastomosis nor suprapubic cystostomy was performed.

\section{Materials and methods}

There were 426 cystectomies performed between June 1999 and December 2009 in the Department and Clinic of Urology in Wroclaw, Poland. In 124 patients, ileal orthotopic bladder replacement with afferent loop was performed. Stenting of the ureterointestinal anastomosis was not performed in any patient in the observed group. The detailed characteristics of the studied population, including age, sex, TNM staging and histological type of tumor are presented in Table 1.

The following were evaluated in the studied group:

i. Frequency of symptomatic urinary tract infections

ii. Time of maintaining the peritoneal drainage

iii. Incidence of the postoperative stricture of the ureterointestinal anastomosis

iv. Duration of surgery

v. Number ofdays of postoperative hospitalization

vi. Number of major complications in the postoperative period.

a. Acute pyelonephritis was diagnosed by the presence of fever above $380 \mathrm{C}$ in the postoperative period. Other potential causes of postoperative bacteraemia including pneumonia, peritonitis, wound infection, phlebitis and epididymitis were excluded. MSU was sent for culture in all patients with fever.

b. Peritoneal drains were removed when the amount of drained fluid did not exceed $50 \mathrm{~mL}$ on two consecutive days. In cases that required peritoneal drainage for over 14days, the measurement of creatinine concentration in the fluid was performed to differentiate the presence of urine and lymph.

c. Ureterointestinal anastomosis stricture was diagnosed by intravenous pyelogram. The examination was performed only subsequent to demonstration of upper tract dilatation on an ultrasound performed with an empty intestinal orthotopic bladder.

d. Duration of the surgery was measured from the moment of the incision of the abdominal wall to its closure.

e. Time of hospitalization was measured in days, excluding the day of surgery. f. Major postoperative complications included death, myocardial infarction, pulmonary embolism, septic shock, respiratory insufficiency and the need for early reoperation (up to 30days after cystectomy).

Table I Characteristics of the studied population

\begin{tabular}{|c|c|}
\hline Total number of patients & 124 \\
\hline \multicolumn{2}{|l|}{ Age [years] } \\
\hline Median & 60 \\
\hline Range & $14-77$ \\
\hline Number of Women (\%) & $10(8)$ \\
\hline Men (\%) & $114(92.0)$ \\
\hline \multicolumn{2}{|l|}{ Histological Grade } \\
\hline G0 (\%) & $2(1.6)$ \\
\hline GI (\%) & $5(4.0)$ \\
\hline G2 (\%) & $28(22.6)$ \\
\hline G3 (\%) & $84(67.7)$ \\
\hline Not evaluated & $5(4.0)$ \\
\hline \multicolumn{2}{|l|}{ Histological type of tumor } \\
\hline Urothelial carcinoma (\%) & $107(86.3)$ \\
\hline Anaplastic carcinoma (\%) & $3(2.4)$ \\
\hline Neuroendocrine carcinoma (\%) & $3(2.4)$ \\
\hline Planoepithelial carcinoma (\%) & $\mathrm{I}(0.8)$ \\
\hline Urothelial + planoepithelial carcinoma (\%) & $5(4.0)$ \\
\hline Adenocarcinoma (\%) & $2(1.6)$ \\
\hline Angiogenic sarcoma (\%) & $\mathrm{I}(0.8)$ \\
\hline Aggressive fibromatosis & I (0.8) \\
\hline Urinary bladder cirrhosis & $\mathrm{I}(0.8)$ \\
\hline \multicolumn{2}{|l|}{ Number of pts with tumor stage } \\
\hline CIS (\%) & $6(4.8)$ \\
\hline T0 (\%) & $15(12.0)$ \\
\hline TI (\%) & $17(13.7)$ \\
\hline T2a (\%) & $17(13.7)$ \\
\hline T2b (\%) & $25(20.2)$ \\
\hline Т3а (\%) & $10(8.0)$ \\
\hline T3b (\%) & $18(14.5)$ \\
\hline T4 (\%) & $15(12.0)$ \\
\hline $\operatorname{Tx}(\%)$ & $\mathrm{I}(0.8)$ \\
\hline \multicolumn{2}{|l|}{ Number of patients } \\
\hline No regional lymph node involvement N0 (\%) & $103(83.0)$ \\
\hline Involvement of regional lymph nodes $\mathrm{N}+(\%)$ & $20(16.1)$ \\
\hline Not evaluated (\%) & $\mathrm{I}(0.8)$ \\
\hline
\end{tabular}


Table continued...

\begin{tabular}{ll}
\hline Total number of patients & 124 \\
\hline Number of patients & \\
\hline No distant metastasis MO (\%) & $122(98.4)$ \\
Distant metastasis present MI (\%) & $2(1.6)$ \\
\hline Number of patients & $36(29)$ \\
\hline Presence of preoperative hydronephrosis (\%) & $88(7 \mathrm{I})$ \\
No preoperative hydronephrosis (\%) & \\
\hline Time of observation (months) & 24.7 \\
\hline mean & $0.25-68$ \\
\hline
\end{tabular}

Cystectomy with bilateral pelvic lymph node dissection was performed in all patients. Orthotopic bladder with afferent loop was created from the ileum. In all patients an S-shaped reservoir was formed. In all patients, the ureterointestinal anastomosis was created with end-to-side method with continuous monofilament 5.0 suture. Suprapubic cystostomy was not used in the observed group. Couvelaire catheter size $\mathrm{Ch} 22$ with additional side apertures was left in the intestinal reservoir, allowing the drainage of urine and intestinal mucus.

In the postoperative period the greatest attention was paid to the hourly diuresis by noting down the urine volume every 2-3hours. Lack of urine or low urine volume with appropriate hydration of the patient was an indicator of a mucus or clot blockage in the catheter. A simple massage of the catheter was in these cases a sufficient maneuver to restore the urine flow. Patients did not require a routine flushing of the reservoir. The Couvelaire catheter was removed on the 21 st day after surgery.

In all patients, peritoneal suction drainage with Redon drains was performed. Two drains were left in the area of the ureterointestinal anastomosis and one in the area of ureterointestinal anastomosis. In all patients, a similar antibiotic treatment plan was used- cephalosporin plus metronidazole for seven days after surgery. In every patient the urine culture was obtained before the surgery.

\section{Results}

a. Pyelonephritis was diagnosed in 10 patients (8\%) (Table 2).

b. Symptoms of pyelonephritis were on average first observed on day 10 (range: 7-15) (Table 3).

c. Mean time of surgery was 6.0hours (4.5-9.0) (Table 4).

d. Mean duration of peritoneal drainage was 7days (range: 3-40) (Table 5).

e. Postoperative days of hospitalization averaged 12days (range: 7-40) (Table 6).

Major complications were observed in 12 patients (9.7\%): 1 death on the 6th day after surgery due to pulmonary embolism, evisceration $(1 \mathrm{pt})$, dehiscence of the intestinal anastomosis (3 pts), lymphorrhea requiring additional drainage ( $2 \mathrm{pts})$, urine leakage and the need for reoperation ( 2 pts), fistula between the intestinal reservoir and vagina in 2 patients (surgical correction), myocardial infarction (1 pt).
Table 2 Results of urinary culture in patients with symptoms of urinary tract infection

\begin{tabular}{lll}
\hline & Type of bacteria & Number of patients \\
\hline \multirow{2}{*}{ Group } & Enterococcus fecalis & 9 \\
& Sterile & I \\
\hline
\end{tabular}

Table 3 The beginning of infection after surgery

\begin{tabular}{lllllll} 
& $\mathbf{n}$ & [days] & $\mathbf{S}$ [days] & $\begin{array}{l}\text { Me } \\
{[\text { days] }}\end{array}$ & $\begin{array}{l}\mathbf{X}_{\min } \\
{[\text { days }]}\end{array}$ & $\mathbf{X}_{\max }$ [days] \\
\hline Group A & 5 & 10 & 1.9 & 10 & 7 & 12 \\
\hline
\end{tabular}

$n$, number; - mean; s, standard deviation; Me, median; $x_{\min }$, minimal value; $x_{\text {max }}$ maximal value

Table 4 Duration of surgery

\begin{tabular}{lllllll}
\hline & $\mathbf{n}$ & $\mathbf{L h}]$ & $\mathbf{S}[\mathbf{h}]$ & $\mathbf{M e}[\mathbf{h}]$ & $\mathbf{x}_{\min }[\mathbf{h}]$ & $\mathbf{X}_{\max }[\mathbf{h}]$ \\
\hline Group A & 124 & 6 & $\mathrm{I} . \mathrm{I}$ & 6 & 4.5 & 9 \\
\hline
\end{tabular}

n, number; - mean; s, standard deviation; Me, median; $x_{\min }$, minimal value; $x_{\text {max }}$ maximal value; $h$, hours

Table 5 Duration of peritoneal drainage

\begin{tabular}{lllllll}
\hline & $\mathbf{N}$ & [d] & $\mathbf{S}[\mathbf{d}]$ & $\mathbf{M e}[\mathbf{d}]$ & $\mathbf{X}_{\min }$ [d] & $\mathbf{X}_{\max }[\mathbf{h}]$ \\
\hline Group A & 124 & 9.1 & 6.2 & 7 & 3 & 40
\end{tabular}

$n$, number; - mean; s, standard deviation; Me, median; $x_{\text {min }}$, minimal value; $x_{\text {max }}$, maximal value; $d$, days

Table 6 Duration of hospitalization after surgery (d-days)

\begin{tabular}{lllllll}
\hline & $\mathbf{N}$ & [d] & $\mathbf{S}[d]$ & $\mathbf{M e}[d]$ & $\mathbf{X}_{\min }[\mathbf{d}]$ & $\mathbf{X}_{\max }[\mathbf{h}]$ \\
\hline Group A & $122 *$ & 14.1 & 6.1 & 12 & 7 & 40
\end{tabular}

$\mathrm{n}$, number; - mean; s, standard deviation; Me, median; $\mathrm{x}_{\min }$, minimal value; $\mathrm{x}_{\max }$, maximal value

\section{Discussion}

Ureteral stents are commonly used in everyday urology practice, although there use is not free of complications. The main purpose of stenting the ureterointestinal anastomosis is to mitigate the consequences of urine leakage and upper urinary tract urinary stasis both of which can be a consequence of kinking of the ureter or temporary edema at the level of the ureterointestinal anastomosis. On the basis of a number of clinical and experimental studies, it has been shown that maintaining the ureteral stents for more than 7 days predisposes to a deleterious consequence, including epithelial metaplasia, incrustation of the ureteral mucosa, stone formation, and edema ulceration of the mucosa and development of moderate hydronephrosis. ${ }^{41-43}$

Stents left in the urinary tract in order to facilitate urine flow, may in the postoperative period paradoxically predispose $t$ infectious complications. Reid's study demonstrated that the mechanism for this ascending urinary tract infection is facilitated bacterial colonization of the stent's surface. ${ }^{28,29}$ In patients with intestinal orthotopic bladder, the small intestine mucosa is the focus of bacterial colonization. ${ }^{29-31,44}$ Draser et al. ${ }^{45}$ have shown the presence of over 10000 microorganisms per 1 milliliter of healthy ileal intestine. Significant bacteriuria is observed in most patients in whom an intestinal segment was used for reconstruction of the lower urinary tract. ${ }^{33-38}$ 
Urine culture obtained at the moment of removal of the catheter from the intestinal reservoir, approximately 3 weeks postoperatively, is positive in all patients. ${ }^{31,39-41}$ This should be linked to a prolonged presence of a fomite; the catheter in the urinary tract and the need for systematic flushing of the reservoir in the postoperative period. Bacteriuria is usually asymptomatic and does not require treatment. Routine use of antibiotics in asymptomatic patients with positive urine culture (over 100,000 bacteria per $1 \mathrm{~mL}$ of urine) may lead to selection of highly resistant pathogens, difficult to eradicate in case of a symptomatic urinary tract infection or urosepsis. Therefore, it is not recommended. $29,33,42-44$

Reid et al., ${ }^{45}$ was the first to demonstrate the formation of biofilms on the ureteral stents and he confirmed the presence of bacterial colonies on the surface of $90 \%$ of silicone double-J stents, although clinical symptoms were observed in only $27 \%$. Subsequently, Farshi has confirmed the presence of bacterial colonies on the surface of $68 \%$ of ureteral stents, although in only $30 \%$ of patients was the urine culture was positive..$^{28,29,45}$ This author has also shown the correlation between the urinary tract infection and the duration of ureteral stenting. ${ }^{46-49}$ Lifshitz $^{9}$ has confirmed the presence of bacterial colonies on the surface of $28-90 \%$ of ureteral stents and significant bacteriuria in only $7-34 \%$ of patients. Therefore, a negative urine culture does not exclude the presence of bacteria on the surface of the stents. Additionally, the author has shown that prophylactic use of antibiotics does not impede bacterial adherence to the surface of the ureteral stents. ${ }^{50-55}$ Liedl \& Hofstetter ${ }^{52,53}$ have shown that each day of maintaining the catheter in the bladder in a closed system (catheterbag) increases the risk of urinary tract infection.

On this basis bacteriuria will be present in almost a $100 \%$ of patients within a month. ${ }^{39,40,56-59}$ In the 1950 s, Kass $^{54}$ showed that maintaining the catheter in the bladder in the open system facilitates urinary tract infections and the presence of bacteriuria was confirmed by the author in a $100 \%$ of patients after only 4 days. It is worth mentioning that in patients with orthotopic bladder with maintained ureteral stents there is a need for systematic flushing of the reservoir (every 3-4hours) in the open system, which facilitates ascending urinary tract infection. ${ }^{60-61}$ Ramsay \& Nickel ${ }^{28,62,63}$ have shown the presence of bacterial biofilms on the surface of all catheters which were left in the bladder for more than 7 days. The additional factor favoring upper urinary tract infection is the retrograde flow of infected contents, which takes place during the essential postoperative reservoir flushing. The stents left in the urinary tract undoubtedly facilitate this process.

Iwakiri ${ }^{60}$ has shown that many patients with orthotopic bladder and pyuria had negative urine cultures. Therefore, in patients with intestinal segment used for the reconstruction of the urinary tract, a urinary tract infection cannot be diagnosed solely on the basis of leukocyturia. The studies of Suriano et al. ${ }^{57}$ confirm this. They demonstrated inversely proportional relations between the number of leukocytes in urine and the number of bacteria in the urinary culture. A small number of leukocytes with a positive urine culture are explained by the tolerance of the intestinal epithelium to bacterial pathogens, (E. coli) a normal commensal of intestine (L). By performing urine analysis in children after Bricker's surgery, Bishop has shown the presence of multiple intestinal epithelial cells, which in routine urine analysis were described as leukocytes. ${ }^{37}$ The presence of two morphologically similar types of cells in urine from patients with intestinal segment used for the reconstruction of the urinary tract may explain the often misdiagnosis of pyuria in these patients.

Taking into consideration the criteria of diagnosis of postoperative urinary tract infection established by the authors, pyelonephritis was diagnosed in 10 patients ( $8 \%$ ). Bricker recommends the use of stents for ureterointestinal anastomosis because the temporary edema of the anastomosis may impede the urinary flow. ${ }^{7}$ However, Regan and Barret $^{39}$ did not show a statistical difference in the frequency of urine leakage and the number of strictures of the anastomosis in patients with or without stenting after Bricker's ileal conduit surgery.

\section{Conclusion}

Conclusion were presented by Skinner, ${ }^{52}$ who has shown that the use of ureterointestinal anastomosis stents after draining the urine with the Bricker approach did not affect the postoperative recovery or the frequency of major early complications. Additionally, the shorter time of hospitalization in patients without stenting is, according to the author, an obvious advantage of this approach. ${ }^{38}$ By analyzing the results of treatment of 200 patients after ileal bladder substitution, Studer observed symptoms of sepsis in 10 patients in the postoperative period, which were mostly due to the blockage of the ureteral stents. The author recommends earlier removal of the ureterointestinal stents-between day 5 and $8 .{ }^{64}$ Furthermore, Mansson ${ }^{8}$ describes a higher frequency of anastomotic stricture formation in patients who have had internal stenting. According to the author, the reason for it is the pressure on the anastomosis area created by a rigid stent, which causes edema and ischemia. ${ }^{65}$

Similarly, Gittes ${ }^{66}$ observes the possibility of two dangerous consequences of the use of the stents. Firstly, there is a risk of blocking the stent by mucus or a blood clot and impeding the urine flow from the upper urinary tract. Secondly, the direct contact of the rigid stent with the ureter wall in the area of anastomosis may cause ischemia and late strictures. In a prospective study evaluating two groups of patients-with and without stents-Mattei has observed three cases of strictures in the group of stented patients. These results have not been statistically significant, due to a small number of patients in the studied groups (29 and 25 patients) ${ }^{67}$ Statistically significant differences were observed in cases of better draining, quicker improvement of intestinal peristalsis and lower frequency of metabolic acidosis in the group with ureterointestinal anastomosis stents. ${ }^{68}$

The urine leakage is improved by good operative technique and efficient drainage of urine from the reservoir. In the group of patients without stenting of the ureterointestinal anastomosis, a Couvelaire catheter with additional side apertures was left in the orthotopic bladder. This catheter allows for efficient flow of urine and intestinal mucus. In light of the presented data, we contend that the routine use of ureteral stents for the supposed facilitation of urine flow is often unnecessary.

The authors found three publications in the urological literature which mentioned that the stenting was not always required after ileal bladder replacement. ${ }^{39,69}$ In the authors' opinion, meticulous and a traumatic ureterointestinal anastomosis and efficient evacuation of urine and mucus from the reservoir (facilitated by the use of a Couvelaire catheter with additional side apertures and regular 2 hourly diuresis), in our experience, obviates the requirement for stenting of the ureterointestinal anastomosis.

\section{Take home message}

Meticulous and a traumatic ureterointestinal anastomosis and efficient evacuation of urine and mucus from the reservoir (facilitated by the use of a Couvelaire catheter), in our experience, obviates the requirement for stenting of the ureterointestinal anastomosis. 


\section{Acknowledgements}

None.

\section{Conflict of interest}

The author declares no conflict of interest.

\section{References}

1. Hautmann RE, Egghart G, Frohneberg D, et al. The ileal neobladder. $J$ Urol. 1998;139(1):39-42.

2. Ali-el-Dein B, el-Sobky E, Hohenfellner M, et al. Orthotopic bladder substitution in women: functional evaluation. JUrol. 1999;161(6):18751881 .

3. Mills RD, Studer UE. Female orthotopic bladder substitution: a good operation in the right circumstances. J Urol. 2000;163(5):1501-1509.

4. Sogni F, Brausi M, Frea B, et al. Morbidity and quality of life in elderly patients receiving ileal conduit or orthotopic neobladder after radical cystectomy for invasive bladder cancer. Urology. 2008;71(5):919-923.

5. Reid G, Denstedt JD, Kang YS, et al. Microbial adhesion and biofilm formation on ureteral stents in vitro and in vivo. J Urol. 1992;148(5):1592-1594.

6. Skinner DG, Boyd SD, Lieskovsky G, et al. Lower urinary tract reconstruction following cystectomy: Experience et results in 126 patients using the Kock ileal reservoir with bilateral ureteroileal urethrostomy. J Urol. 1991;146(3):756-760.

7. Bricker EM. Current status of urinary diversion. Cancer. 1980;45(12):2986-2991.

8. Mansson W, Collena S, Stigsson L. Four methods of ureterointestinal anastomosis in urinary conduit diversion. A comparative study of early and late complications and the influence of radiotherapy. Scand J Urol Nephrol. 1975;13(2):191-199.

9. Lifshitz DA, Winkler HZ, Gross M, et al. Predictive value of urinary cultures in assessment of microbial colonization of ureteral stents. $J$ Endourol. 1999;13(10):735-738.

10. Benson MC, Olsson CA. Urinary diversion. Urol Clin North Am 1992;19(4):779-795.

11. Mazurek LJ, Salska Z, Gniadzik S, et al. Ponadpęcherzowe odprowadzenie moczu za pośrednictwem szczelnego pęcherza jelitowego. Urol Pol. 1984;37(2):111-115.

12. Ashken $\mathrm{MH}$. An appliance-free ileocaecal urinary diversion:preliminary comunication. Br J Urol. 1974;46(6):631-638.

13. Marshall FF. Creation of an ileocolic bladder after cystectomy. J Urol. 1988;139(6):1264-1268.

14. Camay M. Bladder replacement by ileocystoplasty following radical cystectomy. World J Urol. 1985;3(3):161-166.

15. Tscholl R, Leisinger HJ, Hauri D. The ileal S-pouch for bladder replacement after cystectomy: preliminary report of 7 cases. $J$ Urol. 1987;138(2):344-347.

16. Benson MC, Seaman EK, Olsson CA. The ileal ureter neobladder is associated with a high success and a low complication rate. J Urol. 1996;155(5):1585-1588.

17. Kock NG, Ghoneim MA, Lycke KG, et al. Replacement of the bladder by the uretheral Kock pouch: functional results, urodynamics and radiological features. J Urol. 1989;141(5):1111-1116.

18. Cancrini A, De Carli P, Pompeo V, et al. Lower urinary tract reconstruction following cystectomy:experience and resultes in 96 patients using the orthotopic ileal bladder substitution of Studer et al. Eur Urol. 1996;29(2):204-209.
19. Studer UE, Ackermann D, Casanova GA, et al. Three years experience with ileal low pressure bladder substitute. Br J Urol. 1989;63(1):43-52.

20. Reddy PK. The colonic neobladder. Urol Clin North Am. 1991;18(4):609-614.

21. Light JK, Engelmann UH. Le bag: Total replacement of bladder using an ileo colonic pouch. J Urol. 1986;136(1):27-31.

22. Stein JP, Lieskovsky G, Cote R, et al. Radical cystectomy in the treatment of invasive bladder cancer: Long term results in a large group of patients. J Urol. 1998;159:213.

23. Meyer JP, Blick C, Arumainayagam N, et al. A three-centre experience of orthotopic neobladder reconstruction after radical cystectomy:revisiting the initial experience, and results in 104 patients. BJU Int. 2009;103(5):680-683.

24. Obara W, Isurugi K, Kudo D, et al. Eight year experience with Studer ileal neobladder. Jpn J Clin Oncol. 2006;36(7):418-424.

25. Chang SS, Cookson MS, Baumgartner RG, et al. Analysis of early complications after radical cystectomy: results of collaborative care pathway. J Urol. 2002;167(5):2012-2016.

26. Hautmann RE, de Petriconi R, Gottfried HW, et al. The ileal neobladder: complications and functional results in 363 patients after 11 years of follow up. J Urol. 1999;161(2):422-428.

27. Soulie M, Straub M, Game X, et al. A multicenter study of the morbidity of radical cystectomy in select elderly patients with bladder cancer. $J$ Urol. 2002;167(3):1325-1328.

28. Ramsay JW, Crocker RP, Ball AJ, et al. Urothelial reaction to ureteric intubation. A clinical study. Br J Urol. 1987;60(6):504-505.

29. Studer UE, Danuser H, Merz VW, et al. Experience in 100 patients with ileal low pressure bladder substitute combined with afferent tubular isoperistaltic segment. $J$ Urol. 1995;154(1):49-56.

30. Varkarakis IM, Delis A, Papatsoris A, et al. Use of external ureteral catheters and internal double $\mathrm{J}$ stents in a modified ileal neobladder for continent diversion: a comparative analysis. Urol Int. 2005;75(2):139143 .

31. Micali S, De Carli P, Miano R, et al. Double-J ureteral stents: an alternative to external urinary stents in orthotopic bladder substitution. Eur Urol. 2001;39(5):575-579.

32. Tanaka T, Kitamura H, Takahashi A, et al. Long-term functional outcome and late complications of Studer's ileal neobladder. Jpn J Clin Oncol. 2005;35(7):391-394.

33. Ali-el-Dein B, Shaaban AA, Abu-Eideh RH, et al. Surgical complications following radical cystectomy and orthotopic neobladders in women. $J$ Urol. 2008;180(1):206-210.

34. Manoharan M, Ayyathurai R, Soloway MS. Radical cystectomy for urothelial carcinoma of the bladder: an analysis of perioperative and survival outcome. BJU Int. 2009;104(9):1227-1232.

35. Dominguez J, Clase CM, Mahalati K, et al. Is routine ureteric stenting needed in kidney transplantation? A randomized trial. Transplantation. 2000;70(4):597-601.

36. Osman Y, Ali-El-Dein B, Shokeir AA, et al. Routine insertion of ureteral stent in live-donor renal transplantation: is it worthwhile? Urology. 2005;65(5):867-871.

37. Ranganathan M, Akbar M, Ilham MA, et al. Infective complications associated with ureteral Stents in renal transplant recipients. Transplant Proc. 2009;41(1):162-164.

38. Mattei A, Birkhaeuser FD, Baermann C, et al. To stent or not to stent perioperatively the ureteroileal anastomosis of ileal orthotopic bladder substitutes and ileal conduits? Results of a prospective randomized trial. J Urol. 2008;179(2):582-586. 
39. Regan JB, Barrett DM. Stented versus nonstented ureteroileal anastomoses: is there a difference with regard to leak and stricture? $J$ Urol. 1985;134(6):1101-1103.

40. Marx M, Bettmann MA, Bridge S, et al. The effects of various in dwelling ureteral catheter materials on the normal canine ureter. $J$ Urol. 1988;139(1):180-185.

41. Spirnak JP, Resnick MI. Stone formation as a complication of indwelling ureteral stents: a report of 5 cases. J Urol. 1985;134(2):349-351.

42. Choong $\mathrm{S}$, Whitfield $\mathrm{H}$. Biofilms and their role in infections in urology. Br J Urol. 2000;86(8):935-941.

43. McDougal WS. Use of intestinal segments and urinary diversion. In Walsh PC, editor. Campbell*s Urology. 8th ed. USA: WB Saunders Co; 2002. p. 515-602.

44. Wullt B, Holst E, Steven K, et al. Microbial flora in ileal and colonic neobladders. Eur Urol. 2004;45(2):233-239.

45. Reid G, Khoury A, Neumann AW, et al. Components involved in biomaterial-related infections. AUA Update Series. 1992;11:138.

46. Draser B, Shiner M, McLeod GM. Studies on the intestinal flora. I. The bacterial flora of the gastrointestinal tract in healthy and achlorhydric persons. Gastroenterology. 1969;56(1):71-79.

47. Akerlund S, Campanello M, Kaijser B, et al. Bacteriuria in patients with a continent ileal reservoir for urinary diversion does not regulary require antibiotic treatment. BR J Urol. 1994;74(2):177-181.

48. Hill MJ, Hudson MJ, Stewart M. The urinary bacterial flora in patients with three types of urinary tract diversion. $J$ Med Microbiol. 1983;16(2):221-226.

49. Mansson S, Colleen S, Mardh PA. The microbial flora of the continent cecal urinary reservoir, its stoma and peristomal skin. J Urol. 1986;135(2):247-250.

50. Akerlund S, Berglund B, Kock NG, et al. Voiding pattern, urinary volume, composition and bacterial contamination in patients with urinary diversion via a continent ileal reservoir. Br J Urol. 1989;63(6):619-623.

51. Bishop R, Durham-Smith E, Gracey M. Bacterial flora of urine from ileal conduit. J Urol. 1971;105(3):452-455.

52. Skinner DG, Crawford ED, Kaufman JJ. Complications of radical cystectomy for carcinoma of the bladder. J Urol. 1980;123(5):640-643.

53. Liedl Bernhard. Catheter-associated urinary tract infections. Current Opinion in Urology. 2001;11(1):75-79.

54. Liedl B, Hofstetter A. Pathogenese und Verhinderung katheterassoziierter Harnwegsinfektionen. Urologe B. 2000;40(3):233-237.
55. Kass EH. Asymptomatic infections of the urinary tract. Trans Assoc Am Physicians. 1956;69:56-64.

56. Wood DP, Bianco FJ, Pontes JE, et al. Incidence and significance of positive urine cultures in patients with an orthotopic neobladder. $J$ Urol. 2003;169(6):2196-2199.

57. Suriano F, Gallucci M, Flammia GP, et al. Bacteriuria in patients with an orthotopic ileal neobladder:urinary tract infection or asymptomatic bacteriuria? BJU Int. 2008;101(12):1576-1579.

58. Hautmann RE, Miller K, Steiner U, et al. The ileal neobladder:6 years of experience with more than 200 patients. J Urol. 1993;150(1):40-45.

59. Farsi HM, Mosli HA, Al-Zemaity MF, et al. Bacteriuria and colonization of double-pigtail ureteral stents: long-term experience with 237 patients. J Endourol. 1995;9(6):469-472.

60. Iwakiri J, Freiha FS, Shortliffe LM. Prospective study of urinary tract infections and urinary antibodies after radical prostatectomy and cystoprostatectomy. Urol Clin North Am. 2002;29(1):251-258.

61. Studer UE, Casanova GA, Zingg EJ. Bladder substitution with an ileal low-pressure reservoir. Eur Urol. 1988;14(Suppl 1):36-39.

62. Nickel JC, Grant SK, Costerton JW. Catheter-associated bacteriuria. A experimental study. Urology. 1985;26(4):369-375.

63. Ramsay JW, Garnham AJ, Mulhall AB, et al. Biofilms, bacteria and bladder catheters. Br J Urol. 1999;64(4):395-398.

64. Sagalowsky AI. Early results with split-cuff nipple ureteral reimplants in urinary diversion. J Urol. 1995;154(6):2028-2031.

65. Studer UE, Zingg EJ. Ileal orthotopic bladder substitutes. What we have learned from 12 years experience with 200 patients? Urol Clin North Am. 1997;24(4):781-794.

66. Gittes RF. To stent or not to stent? J Urol. 1985;134(6):1179.

67. Lee KS, Montie JE, Dunn RL, et al. Hautmann and Studer orthotopic neobladder: a contemporary experience. J Urol. 2003;169(6):21882191.

68. Le Duc A, Camey M, Teillac P. An original antireflux uretero ileal implantation technique: long-term follow up. J Urol. 1987;137(6):11561157.

69. Sedor J, Mulholland SG. Hospital-acquired urinary tract infections associated with the indwelling catheter. Urol Clin North Am. 1999;26(4):821-828. 